\title{
A Comparative Analysis on Smart Farming Techniques using Internet of Things (IoT)
}

\author{
${ }^{\text {*1 }}$ Pramod Mathew Jacob, ${ }^{2}$ Prasanna $\mathrm{M},{ }^{3}$ Parveen Sultana $\mathrm{H}$ \\ ${ }_{1,2,3}$ VIT University, Vellore, Tamil Nadu, India \\ Email: ${ }^{*}$ ramod3mj@gmail.com, prasanna.m@vit.ac.in, hparveensultana@vit.ac.in
}

Received: 10 $^{\text {th }}$ December 2017, Accepted: 8th February 2018, Published: 28th February 2018

\begin{abstract}
Agriculture is considered as one of the major sources in maintaining a nation's GDP. Most of the developing countries and under developed countries are relying on cultivation to improve their economic wealth. In this modern technology era, technology can play a tremendous role in the agriculture sector. The advanced technology has the capability to automate various cultivation phases like watering, fertilizing, harvesting and much more. In order to make the cultivation phases smarter, we deploy smart sensors in the fields to sense the water level, photo sensors to ensure sufficient sunlight is available for plant's growth, sensors to sense the nitrogen content and thereby to inform the farmer to initiate steps for proper fertilizing, etc. There are many works done in this area, and much more is progressing in the labs now. We analyzed the various standard IoT techniques used in Agriculture sector based on hardware and software, and thereby deriving the existing challenges for making farming much smarter and efficient.
\end{abstract}

Keywords: Smart farming, Internet of Things (IoT), IoT in agriculture, Sensors

\section{Introduction}

Internet of Things (IoT) is a term which was quite unfamiliar to ordinary people in older days. But in this era of smart technology and smarter systems, IoT became much popular. IoT is an emerging field which can play a vital role in almost all fields and disciplines including agriculture, health sector, home automation, aviation and transport, defense and military applications and much more. The Internet of things (stylized Internet of Things or IoT) is the internetworking of physical devices, vehicles (also referred to as "connected devices" and "smart devices"), buildings, and other items - embedded with electronics, software, sensors, actuators, and network connectivity that enable these objects to collect and exchange data. IoT can be used to make the objects or things smarter by remotely sensing or controlling it. Internet of Things comprises things that have unique identities and are connected to the internet [2]. IoT describes a system consist of various items in the physical world, and sensors within or attached to these items which are connected to the Internet via wireless and wired Internet connections. These sensors can use various types of local area connections such as RFID,
NFC, Wi-Fi, Bluetooth, and Zig-bee. Sensors can also have wide area connectivity such as GSM, GPRS, 3G, and

LTE.

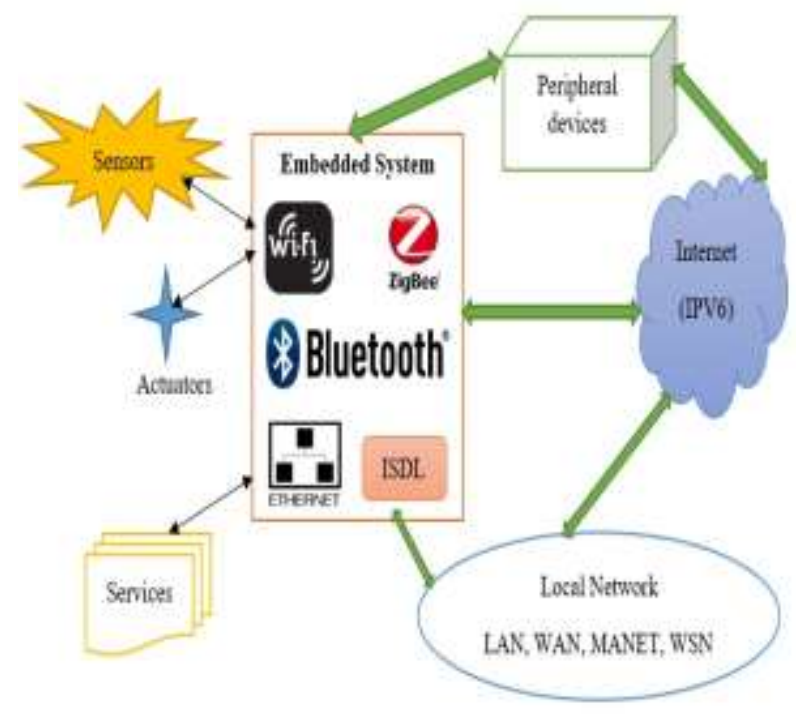

Figure 1. Typical Architecture of Internet of Things

The typical IoT architecture is illustrated in Fig. 1. It is simply a networked set of devices and software embedded components. The embedded system consist of a mini processor or boards which have some processing capability. For example Arduino, Raspberry PI, Intel Galileo, etc. IPV6 addressing used for IP addressing though it can address up to millions of devices. There will be some application domain where the central things or sensors are deployed for monitoring and controlling. It will sense the relevant information and will pass towards some CyberPhysical System (CPS) which performs the computation and coordination. A typical IoT possesses the following characteristics:

Connectivity: All the devices, sensors and equipment should be connected each other through a secure network.

Things: Things' in IoT perspective can be a wide variety of devices such as biochip transponders on pet animals or farm animals, heart monitoring implants, electric clams in coastal waters, automobiles with built-in sensors, DNA analysis devices for environmental/food/pathogen monitoring or field operation devices that assist firefighters in search and rescue operations [3]. Things may be actuators or 
sensors which collect necessary data and transfer across the IoT system.

Data: Data is the adhesive agent in Internet of Things, which initiates action and intelligence.

Communication: Every component or things are communicating with each other for data transfer or for initiating system monitoring and controlling. Communications are usually initiated by using wireless protocols.

Intelligence: Sensors usually make the IoT devices intelligent with some processing element for data analytics and pre-processing.

Action: It can be either manual or action based upon debates regarding phenomena (for instance in climate change decisions) and automation, usually initiated by actuators.

Ecosystem: The environment or domain of the Internet of Things

Most of the countries primary source of income is agriculture. Agriculture and crops play a significant role in improving the country's welfare and prosperity. But due to unexpected climate variations and lack of enough labors to perform the agriculture-related jobs, agriculture sector faces a pathetic crisis. Agriculture is one of the disciplines where IoT can do much. The challenges in agriculture sector include improper watering to plants, Deficiency of needed fertilizers for the proper growth of plants, unnoticed attacks of pests and insects, unexpected change in climate or occurrence of natural calamities, etc. The above said challenges are addressed by IoT, and the existing IoT applications are capable of solving these issues. IoT can perform an appreciable task by deploying sensors in the fields to monitor various factors like water level, temperature level, humidity level, soil PH values, fertilizer content in soil, etc. and hence monitoring and controlling the various farming phases.

There are many researchers who worked in this field with the aim of making farming techniques and methodologies much smarter and intelligent. We have analyzed the various IoT applications and products that can be applied in agricultural sectors and derived the existing challenges in this domain that are yet to be solved or not addressed by the researchers.

\section{LITERATURE REVIEW}

We have gone through nearly 30 journal papers which discuss some smart agriculture techniques. But during the analytical review, we came to identify that the underlying architecture or concept used in some papers are similar. So we refined our literature with a representative work from each cluster of papers using a similar architecture.
Lan Diu et al. [4] proposed a Greenhouse environment monitoring system using IoT technology. They used Zig-bee technology [5] and Wireless Sensor Network (WSN) nodes to control the environmental data. The front end of the system performs data acquisition and processing, transmission and reception of data between various nodes. The temperature is sensed using a temperature sensor and is processed by a data terminal node. The processed data is sent to an intermediate node using WSN. This intermediate node aggregates all the information and is fed to the Personal Computer (PC) through its serial port. Humans can view the data and remotely collect the information regarding the temperature conditions in the greenhouse. The advantage of this system is low cost with moderate reliability. It also reduces the manpower in cultivation. But it doesn't address the humidity and sunlight constraints inside a greenhouse.

Ram et al. [6] proposed an IoT system for regulating water in the agricultural fields. The main functionalities of their system are to supply water when the field is dry and removing excess water from the field. The system consists of a water level indicating sensor which senses the water level in the field and sends it to a mobile device. Their embedded IoT kit consists of a sensor and two water pipes: One for pumping water and one for sucking the water from the field. Hybrid solar panels are connected to the system, though solar power is considered as the primary source of power for the system. Soil hygrometer is used to sense the moisture level in the soil. They are claiming that their system reduces human effort and increases the productivity.

Shenoy and Yogesh [7] proposed an IoT-based architecture for poly-house [8]. IoT can be used to increase productivity by controlling factors like soil $\mathrm{pH}$ [9], soil moisture, humidity temperature, the rate of soil nutrients, etc. They proposed an IoT model for controlling and monitoring the plant growth. Moisture in the soil and $\mathrm{pH}$ of the soil is measured using suitable potentiometers at various instances and is transferred to the pumps which provide irrigation using Bluetooth or Wi-Fi. Poly-house opens or closes the flaps to blow air based on the temperature sensed by the temperature sensor. A central server will initiate sprinklers when the humidity is low. $\mathrm{pH}$ value is maintained by adding an adequate quantity of alkaline and acidic fertilizers based on the sensed $\mathrm{pH}$ value. $\mathrm{pH}$ sensor is used to sense $\mathrm{pH}$ value. Thus they make the farming phase smarter using the IoT technology. In harvesting level, they use robotic arms embedded with a camera to identify the crops to be harvested. Image recognition algorithm is used to sense the color and the shape of the crop to be plucked. RFID tags are attached to each collected crop. This RFID tag makes the packing and transportation of crops easier. In the destination 
terminal, the RFID tags are removed and are sold to the end user. Thus their model addresses almost all phases of a crop from production till delivery to end consumers. They used Arduino based system with integrated shields for sensors, GPS module, and RFID tags. The disadvantage of their system is all about the accuracy of robotic arms and image recognition phases. The claim that the success margin is nearly $60 \%$ and can be much improved by using better algorithms and hardware components.

Abdulla et al. [10] proposed AgriSys, an IoT-based system for analyzing the agriculture environment and maintaining the adequate requirements for cultivation. It deals with the various challenges in a farming sector like temperature, humidity, $\mathrm{pH}$ and nutrient levels, etc. They adopted fuzzy control for a reduced controller complexity and have used LabView for programming aspects. AgriSys is developed using Phidget interface $8 / 8 / 8$ [11]which is integrated with light sensors, temperature / humidity sensors, $\mathrm{pH}$ sensors, soil moisture sensor and soil temperature sensor. The system is used to control sunlight, temperature, and waterfall over the cropped plant which is a necessity for greenhouses. A water pump is attached to the system. Whenever the soil moisture is less than the threshold value, water is pumped up through the hose and is sprinkled over plants. Depending on the plant humidity and field water level information, the pump keeps on sprinkling. A motor is used for automating the shading inside greenhouse depends on the estimated needs of the plant. The system complexity and number of used components are reduced by introducing fuzzy inference system. AgriSys uses MIMO (Multiple Input Multiple Output) [11] system architectures, though multiple data is sensed through various sensors at a time, and multiple actuation is to be carried out based on sensed information. AgriSys is deployed on a web server for making it available for all the time. Their evaluation results state that they have achieved increased productivity with enhanced safety and easier farming procedures.

Nikesh and Kawika [12] proposed a smart agricultural schema using IoT and WSN techniques. Their system consist of a GPS enabled Robot which can perform activities like weeding, water spraying, soil moisture sensing, scaring the birds and animals, surveillance of the field, etc. It consists of an intelligent irrigation system which suitably irrigates the field based on the real-time data. Their project also comprises of a smart warehouse management schema which performs actions like temperature maintenance, humidity maintenance, and theft detection. All these functionalities are performed with the aid of using interfacing sensors, High-resolution image capturing device, Wi-Fi or Zig-bee based systems [5], actuators integrated with microcontrollers and Raspberry PI [13]. Test results show that various field and warehouse activities can be automated using wireless communication and IoT-based activities. The robot is powered using an external power source and is connected with microcontrollers and Raspberry PI module. Their embedded kit consist of PIR motion sensor, temperature, and humidity sensors, cooling fan and a water pump all connected to a microcontroller board. There result in claims that it is a total solution for making the agriculture sector smarter.

Nagothu [14] proposed an automatic field watering system using ARM processor. A soil sensor is used to sense the soil moisture content. The system captured the weather information from a weather forecasting website which is used to predict the need for sprinkling water in the upcoming days. The data from the website is a load to the microcontroller using UART which controls the water system. The system can be controlled using an Android App or a remote PC by sending messages using GPRS. When the sensor detects the dryness of the soil, the system checks the possibility of occurring rain using the weather forecasting information. If there is no possibility of raining, the water is sprinkled in the field. The advantage is that, it reduces the wastage of water though it incorporates the possibility of raining for decision making. But the accuracy of weather prediction is not yet stabilized to trust this system.

Nikhil and Smita [15] proposed a water dripping scheme that will inject water directly into the root base of a plant. The system uses Raspberry PI [13] and Arduino [16] boards with Zig-bee modules. The system is cost effective and scalable and uses star Zigbee topology [5] for communication between devices. All devices are connected to the Raspberry PI which acts as the central coordinator. They implemented it for a small house garden of 50 plant pots which is all connected together using a small water pipeline network in the base of all plant pots. So that the water sprinkled will be directly fed to the roots of the plant under the topsoil level. Watering can be done by sending an email message to the GPS module embedded with the central system. They use ultrasonic sensors and solenoid valves to design the smart irrigation system. Ultrasound sensors are used to measure the water level in the tank. But the limitation of this system is that it is not sensing the moisture content in the plant pots. Hence the user should manually initiate actions regarding when to water the system.

Putjaika et al. [17] proposed an Arduino [16] based control system for intelligent farming in Thailand. The intelligent farming system comprises of two modules named as sensor system and control system. Their work mainly focuses on the control system in which they control the watering and roofing of an outdoor farm based on data which are statistically collected and processed from sensor systems. The data includes 
temperature, humidity, moisture and light intensity using suitable sensors. The sensed values are fed to a centralized server using a WiFi module. Based on the sensed information they develop a decision table to initiate the actuators that are using in their proposed system. By using Kalman filtering [18], they resolved the issue of reducing noises in the sensed data from the sensors. This Kalman filtered smoothened data is fed to the decision system to generate the decision table. The weather information is also inputted in the decision table to derive the decisions more precisely and accurately. Their system will predict the weather conditions based on decision table parameters. They developed a mobile application to manually adjust the watering and roofing of the farm using commands or messages. They developed a mini prototype model to validate their system. But they didn't address the scalability issues when this model is applied to a large agricultural farm field. Lack of a fertilizer sensing module is a major disadvantage of this system.

Ayush et al. [19] proposed an IoT-based image processing technique to monitor the plants and crops in an agricultural field. It combines the best features of image processing and IoT technology. It uses temperature and humidity sensors to estimate the climatic conditions in the field. After estimating that, it checks the value of the soil moisture content using suitable soil sensors. If the moisture content is below prescribed level, suitable actions are initiated by the central system to water the crops. It periodically captures the images of plant leaves and is fed to an image processor. Using MATLAB [20] and image processing algorithms, the system determines the health of plants from the captured image of a plant leaf. The system is trained with the set of images of plant leaf in various healthy conditions and climatic variations. The captured image is mapped with the system to determine the actions to be initiated to improve the plant strength. The advantage of this system over other existing smart technologies in agriculture sector is that it determines and initiates actions based on the captured image of the plant. The limitation of this system is the accuracy of image processing algorithms for various data sets, which is not finitely trustable.

Based on the inferences and findings from the above list of works in smart farming, we performed a comparative analysis of the methodologies and technologies used. The summary of our comparative study is discussed in the next section.

\section{SYSTEM ANALYSIS AND RESULTS Hardware Architecture}

There are many methodologies and works performed in the area of smart farming. Every work paves the way for the upcoming researcher to explore more. The agricultural sector is in need of some automation techniques and tools with smart technology. Internet of Things paves the way for achieving this feat by deploying various smart devices in the field and constantly monitoring the climatic and soil conditions. All the above-discussed works mainly focus on temperature and humidity constraints, the moisture content of the soil, fertility level of soil, etc. Most widely used IoT processors include Raspberry PI, Arduino and ARM processors. . We summarize the works with various physical and logical resources used in their IoT system as illustrated in Table 1.

Wireless Fidelity (Wi-Fi) is the communication technology used in most smart farming systems. In IoT system for agriculture [7], the sensed $\mathrm{pH}$ value and soil moisture content are updated to the central coordinator using Wi-Fi communication. Smart Agriculture using IoT and WSN [11] project uses WiFi communication in a much productive manner. They have implemented Wireless routers in the field as well as the smart warehouse. The sensed temperature and humidity information, captured images of the field is sent to the Raspberry PI processor, which processes the data and send a command to actuate necessary actuations using wireless communication. A control system for intelligent farming [16] uses a centralized server with Wi-Fi module. All the sensed values were updated to the central server, and suitable actions are initiated by issuing commands using wireless communication. Wi-Fi is used due to its operating range (2-100meters) and uses a frequency band of $2.4 \mathrm{GHz}$. The key challenge in using Wi-Fi communication is it consumes much power which cannot be tolerated in an IoT-based system. Zig-bee protocol is the alternative for that.

Zig-bee communication protocol is followed in Intelligent Agriculture Greenhouse monitoring system [4], Smart Agriculture using IoT and WSN [11] and Smart drip irrigation systems [14]. Zig-bee is used though it consumes less power and is low in cost. It is easier to implement and deploy compared to other alternatives. Zig-bee uses small packets compared to Bluetooth and Wi-Fi. It supports star, tree, mesh, cluster tree topologies which operate at different frequency bands $(2.4 \mathrm{GHz}, 868 \mathrm{MHz}, 915 \mathrm{MHz})$.

Intelligent Agriculture Greenhouse monitoring system [4] also uses the 6LoWPAN protocol which is mainly intended for low powered wireless devices. It allows using 128 bit IP address in 802.15.4 radios. It supports header compression and addresses translation techniques. IPv6 packets are compressed and encapsulated so that it will work well in standard 802.15.4 packet frames. It can be applied in M2M applications, Smart grid systems, and IoT-based system. The biggest advantage of using 6LoWPAN is scalability though it supports $2^{128}$ IP addresses. Like Zig-bee, it supports tree and mesh network topologies and operates on the same frequency band as that of 
Zig-bee.

Comparing about the central processing boards, Arduino and Raspberry PI is the most widely used boards due to its easiness in interfacing various sensors and external hardware components. Arduino is a microcontroller which can run the program over and over again whereas Raspberry PI is a mini computer which can simultaneously run multiple programs. Arduino is more robust than Raspberry PI though it is a plug and play device. Raspberry PI cannot be used in power constrained applications though it requires much power to operate than that of Arduino boards. Arduino boards are more preferred in IoT systems which used for monitoring and controlling. Raspberry PI is used in IoT applications which need some information from remote servers or from some other external agencies. Inbuilt Wi-Fi module and Bluetooth modules in Raspberry PI make it more applicable to web service based IoT applications.

Table 1. Summary based on physical and logical resources used

\begin{tabular}{|c|c|c|c|c|}
\hline IoT system & $\begin{array}{l}\text { Microcontroller or } \\
\text { Board used }\end{array}$ & $\begin{array}{l}\text { Software } \\
\text { platform used }\end{array}$ & Sensors used & $\begin{array}{l}\text { Communication } \\
\text { Technologies used }\end{array}$ \\
\hline $\begin{array}{l}\text { Intelligent Agriculture } \\
\text { Greenhouse } \\
\text { monitoring system }\end{array}$ & $\begin{array}{l}\text { CC2530 chip, } \\
8051 \text { microcontroller, } \\
\text { STM8S103F3 chip }\end{array}$ & LabView & $\begin{array}{l}\text { Temperature sensor } \\
\text { Humidity sensor } \\
\text { Pressure sensor } \\
\text { Light sensor }\end{array}$ & $\begin{array}{l}\text { Zig-bee, } \\
\text { GPRS, } \\
802.15 .4 \\
\text { (6LowPAN) }\end{array}$ \\
\hline $\begin{array}{l}\text { Water regulation in } \\
\text { field using IoT }\end{array}$ & Not mentioned & Not mentioned & $\begin{array}{l}\text { Soil hygrometer, } \\
\text { VRS-20 SDI-12 radar } \\
\text { sensor, RFID }\end{array}$ & GSM \\
\hline $\begin{array}{l}\text { IoT system for } \\
\text { agriculture }\end{array}$ & Arduino board & $\begin{array}{l}\text { Arduino IDE, } \\
\text { Open CV }\end{array}$ & $\begin{array}{l}\text { Humidity, } \\
\text { Temperature, } \\
\text { Soil moisture }\end{array}$ & $\begin{array}{l}\text { Bluetooth, } \\
\text { Wi-Fi }\end{array}$ \\
\hline $\begin{array}{l}\text { AgriSys -Smart and } \\
\text { ubiquitous controlled } \\
\text { environment } \\
\text { agricultural system }\end{array}$ & $\begin{array}{l}\text { Phidget interface } \\
8 / 8 / 8\end{array}$ & LabView & $\begin{array}{l}\text { Humidity sensor } \\
\text { Temperature sensor } \\
\text { Soil moisture sensor } \\
\text { Light sensor } \\
\text { pH sensor } \\
\text { Thermocouple sensor }\end{array}$ & GSM \\
\hline $\begin{array}{l}\text { Smart Agriculture } \\
\text { using IoT and WSN }\end{array}$ & $\begin{array}{l}\text { Raspberry PI, } \\
\text { AVR microcontroller }\end{array}$ & Raspbian OS & $\begin{array}{l}\text { Humidity sensor } \\
\text { Temperature sensor } \\
\text { Soil moisture sensor } \\
\text { PIR motion sensor } \\
\text { Ultrasonic sensor }\end{array}$ & $\begin{array}{l}\text { GPS } \\
\text { WSN } \\
\text { Wi-FI } \\
\text { Zig-bee }\end{array}$ \\
\hline $\begin{array}{l}\text { Weather based smart } \\
\text { watering system }\end{array}$ & ARM processor & Android App & Soil moisture & GPRS \\
\hline $\begin{array}{l}\text { Smart drip irrigation } \\
\text { system }\end{array}$ & $\begin{array}{l}\text { Raspberry PI, } \\
\text { Arduino board }\end{array}$ & $\begin{array}{l}\text { Arduino IDE, } \\
\text { Python }\end{array}$ & Ultrasonic sensor & $\begin{array}{l}\text { Zig-bee, } \\
\text { GPS }\end{array}$ \\
\hline $\begin{array}{l}\text { A control system for } \\
\text { intelligent farming }\end{array}$ & Arduino board & Arduino IDE & $\begin{array}{l}\text { Humidity sensor } \\
\text { Temperature sensor } \\
\text { Soil moisture sensor } \\
\text { Light intensity sensor }\end{array}$ & Wi- Fi \\
\hline $\begin{array}{l}\text { Smart agriculture } \\
\text { using IoT and image } \\
\text { processing }\end{array}$ & Arduino board & $\begin{array}{l}\text { MATLAB, } \\
\text { Arduino IDE }\end{array}$ & $\begin{array}{l}\text { Soil moisture sensor } \\
\text { Temperature sensor } \\
\text { Humidity sensor } \\
\text { Serial JPEG camera } \\
\text { module }\end{array}$ & Wi- Fi \\
\hline
\end{tabular}

\section{Software Architecture}

Software Architecture plays a vital role in the design of an efficient and effective IoT system [22]. Software architecture of a system consist of various elements or modules in that system, relationship between those components and external visible features of those elements [23]. It is a herculean task for the designer to choose the suitable architectural patterns for various IoT based use case scenarios. In Smart farming various widely used architectural patterns includes Client - Server, Publish - Subscribe, Representational State Transfer (REST) and Peer- Peer style. 
We have evaluated the capabilities and performance of various architectural styles based on the parameters like Availability, Scalability, Interoperability, Security, Ease of design etc. These are considered as the various constraints that can be used for determining the suitable software architecture schema to be used in an IoT based system. For experimental analysis, we replicated various IoT based smart farming systems using various software architectural patterns like Client - Server, Peer- Peer, Publish - Subscribe and REST. IoT can perform an appreciable task by deploying sensors in the fields to monitor various factors like water level, temperature level, humidity level, soil PH values, fertilizer content in soil etc. and hence monitoring and controlling the various farming phases. We executed a case study using various software architectural patterns as mentioned below.

Case 1: Smart Irrigation System using Client-Server

A soil sensor is used to sense the soil moisture content. The system captured the weather information from a weather forecasting website which is used to predict the need of sprinkling water in the upcoming days. The data from the website is loaded to the microcontroller which controls the water system. The system can be controlled using an Android App or a remote PC by sending messages using GPRS. When the sensor detects the dryness of the soil, the system checks the possibility of occurring rain using the weather forecasting information. If there is no possibility of raining, the water is sprinkled in the field.

\section{Case 2: Smart Irrigation System using REST}

A soil sensor is deployed in the field. The central coordinator periodically initiate request for moisture level. The sensor sent the value to the server. The central coordinator initiates command to the water sprinklers to sprinkle water if the soil moisture content is below par level. It's a light weight architecture and initiates action only when the system initiates request. A session is created in each instance.

\section{Case 3: Smart Irrigation System using Peer - Peer}

In this case sensor processing units are deployed at various parts of the agricultural field. Each sensor unit updates the sensed soil moisture level.
By analyzing the soil moisture values of various regions, the system will initiate water sprinkling. In this case the moisture level sensed by neighboring processing nodes is also analyzed to initiate the water sprinklers. Each processing node is connected with all other processing nodes and each node is embedded with a soil moisture sensor and a water sprinkler. They used to communicate each other through Wi-Fi or ZigBee standards.

\section{Case 4: Smart Irrigation System using Publish-} Subscribe

This is implemented as similar to peer- peer case scenario. Instead of deploying processing units in every parts, we deployed a central coordinator to which all sensors and water sprinklers are connected. The sensors periodically updates the soil moisture content to the central coordinator (Publisher). The central coordinator issues commands to various water sprinklers deployed in multiple regions where which the moisture content is less. In this case the water is sprinkled only in the regions with less soil moisture value though the central coordinator actuates only selected sprinklers (Subscriber).

We implemented the above four systems using Raspberry PI and Arduino boards along with soil moisture sensors in our experimental analysis. Though security is not a major concern in this scenario, we evaluated the performance aspects of these systems. The various parameters that we considered are availability, reliability, scalability and interoperability.

Availability 'A' of the system is calculated using

$\mathrm{A}=\frac{M T B F}{M T B F+M T T R}$

Where:

MTBF: Mean Time Between Failures

\section{MTTR: Mean Time To Repair}

We evaluated all the four systems for a period of 24 hours to measure the system availability. The measured values are rounded up to the nearest integer as shown in Table 2. 
Table 2: Estimated Availability of architectural patterns

\begin{tabular}{|l|l|l|l|}
\hline Architectural pattern & $\begin{array}{l}\text { MTBF } \\
\text { (hours) }\end{array}$ & $\begin{array}{l}\text { MTTR } \\
\text { (hours) }\end{array}$ & Availability \\
\hline Client-Server & 23 & 0.3 & $98.71 \%$ \\
\hline Peer - Peer & 23.8 & 0.1 & $99.58 \%$ \\
\hline Publish - Subscribe & 22.5 & 0.8 & $96.56 \%$ \\
\hline REST & 22.8 & 0.3 & $98.70 \%$ \\
\hline
\end{tabular}

Scalability is measured by following load scalability. We evaluated the system by performing vertical scaling. We add the load of the central coordinator by adding more sensors and actuators. Though we make every node as processing element in Peer - Peer architecture, we can measure the performance tuning versus hardware scalability. It is much better to add more processing nodes instead of increasing the capability and capacity of a single node. It can be computed using Amdahl's law:

Speed $=\frac{1}{\alpha+\frac{1-\alpha}{P}}(2)$
P: Number of processing nodes

$\alpha$ : Fraction of computation that is sequential

1- $\alpha$ : Fraction of computation that can be parallelized

The computed scalability metrics based on performance tuning for the various case study models are illustrated in Table 3.

Table 3: Estimated performance tuning of architectural patterns

\begin{tabular}{|l|l|l|l|}
\hline Architectural pattern & $\begin{array}{l}\text { Number of } \\
\text { processing nodes }\end{array}$ & $\begin{array}{l}\text { Sequential } \\
\text { Computation } \\
\text { Fraction (a) }\end{array}$ & Speed \\
\hline Client-Server & 2 & 0.2 & 1.66 \\
\hline Peer - Peer & 4 & 0.1 & 3.07 \\
\hline Publish - Subscribe & 1 & 0.6 & 1 \\
\hline REST & 1 & 0.4 & 1 \\
\hline
\end{tabular}

Interoperability concerns how well the discrete system components works together. Ducq et al proposed a quantitative metric model [24] for measuring interoperability but is not widely accepted. Still interoperability is a sort of qualitative metric. We evaluated the interoperability of various architectural patterns by retrieving opinions from software architects and academicians works in IoT fields. Based on their experience and knowledge they used to rate the interoperability capability of each architectural pattern in a point scale of 1 to 5 . Point 1 shows less interoperability and it slightly increases for each point, where point 5 shows strong interoperable capability. We also requested the experts to rate the ease of design for each architectural pattern. We estimated the average rating for each architectural pattern based on expert feedback and is shown in Fig. 2.

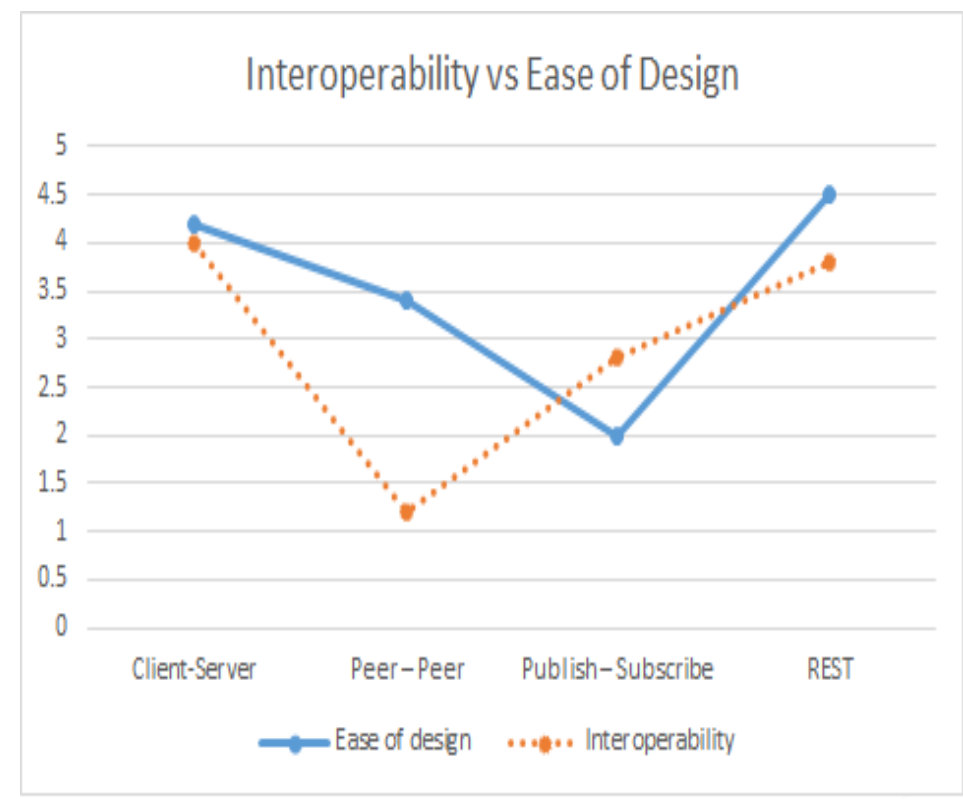

Figure 2. Interoperability vs Ease of design for 


\section{architectural patterns}

Security and Privacy can be ensured by providing authentication and authorization in each layer of Publish - Subscribe architectural style. Asymmetric public key cryptography in device level and PGP can be considered as a method of creating SSL sessions between devices and applications. Device management policies like usage of device identity, device registration, secure key registration etc. can be followed along with end - end encryption in storage and transmission of data. Based on the system architectural analysis we derived the following characteristics as shown in Table 4 for each

Table 4: Comparison of architectural styles based on nonfunctional capabilities

\begin{tabular}{|l|l|l|l|l|}
\hline Parameters & $\begin{array}{l}\text { Client- } \\
\text { Server }\end{array}$ & $\begin{array}{l}\text { Peer } \\
\text { Peer }\end{array}$ & $\begin{array}{l}\text { Publis } \\
\text { Subscr } \\
\text { ibe }\end{array}$ & REST \\
\hline Availability & Low & High & $\begin{array}{l}\text { Margin } \\
\text { al }\end{array}$ & $\begin{array}{l}\text { Margin } \\
\text { al }\end{array}$ \\
\hline Scalability & High & High & Less & Less \\
\hline Reliability & $\begin{array}{l}\text { Margin } \\
\text { al }\end{array}$ & High & $\begin{array}{l}\text { Margin } \\
\text { al }\end{array}$ & Less \\
\hline $\begin{array}{l}\text { Performan } \\
\text { ce }\end{array}$ & Less & High & $\begin{array}{l}\text { Margin } \\
\text { al }\end{array}$ & Less \\
\hline $\begin{array}{l}\text { Ease } \\
\text { system } \\
\text { design }\end{array}$ & Easier & $\begin{array}{l}\text { Margin } \\
\text { al }\end{array}$ & $\begin{array}{l}\text { Difficul } \\
\text { t }\end{array}$ & Easier \\
\hline Security & $\begin{array}{l}\text { Suppor } \\
\text { ted }\end{array}$ & $\begin{array}{l}\text { Cannot } \\
\text { guarant } \\
\text { eed }\end{array}$ & $\begin{array}{l}\text { Suppor } \\
\text { ted }\end{array}$ & $\begin{array}{l}\text { Cannot } \\
\text { guarant } \\
\text { eed }\end{array}$ \\
\hline $\begin{array}{l}\text { Interopera } \\
\text { bility }\end{array}$ & $\begin{array}{l}\text { Suppor } \\
\text { ted }\end{array}$ & $\begin{array}{l}\text { Not } \\
\text { support } \\
\text { ed } \\
\text { provide } \\
\text { d }\end{array}$ & $\begin{array}{l}\text { Provide } \\
\text { d }\end{array}$ & $\begin{array}{l}\text { Not } \\
\text { provide } \\
\text { support } \\
\text { ed }\end{array}$ \\
\hline
\end{tabular}

\section{Conclusion}

Internet of Things (IoT) is playing an appreciable role in all fields of the globe like agriculture, aviation, transport, health care, etc. Our work reviews the growth and progress of IoT-based system used in the agriculture sector and in smart farming. It all started by using Zig-bee based Wireless Sensor Networks (WSN) later followed by centralized IoT boards and processors like Arduino, Raspberry PI, etc. They are using a wide set of sensors like temperature and humidity sensor, light sensor, soil moisture sensor, $\mathrm{pH}$ sensor, PIR motion sensor, etc. The main challenge for the researchers in this area is to design more accurate and useful sensors that will aid in monitoring plant growth. Power management to the sensors and central system is also a constraint. Designers should opt for low powered intelligent sensors and board to use the power efficiently. On the software side our analysis may help the software architect to choose the suitable architectural models. A software architect can map his various system requirements or constraints with the various parameters considered in Table 4. Based on the constraint cases, they can choose an architectural design which is much suitable and relevant for their IoT based system. Usage of suitable architecture will provide easiness for deriving the test cases in the software testing phases [25]. Different architectural patterns are applicable for different IoT use cases. It will be much effective if the architect choose a pattern in such a manner that it can be reusable for similar use case classes.

pattern for their IoT use case. Our review analysis shows that IoT is still an exploring area for the researchers to make the farming much smarter by designing much smarter objects or things using secure and interoperable software architectures.

\section{Acknowledgments}

We express our sincere gratitude to Ms. Kuppam Sameera for her support and guidance provided during our survey work.

\section{References}

[1] T. Qiu, J. Liu, W. Si, M. Han, H. Ning and M. Atiquzzaman, "A Data-Driven Robustness Algorithm for the Internet of Things in Smart Cities," in IEEE Communications Magazine, vol:55, no:12, p. 18-23, DECEMBER 2017.

[2] A. Bahga and V. MAdisetti, Internet of Things: A hands on approach, Universities Press, First edition, ISBN: 97888173719547.

[3] Y. Erlich, "A vision for ubiquitous sequencing," Genome Research, ISSN 1088-9051, 2015, p. 1411-1416.

[4] L. Dan, C. Xin, H. Chongwei and J. Liangliang, "Intelligent Agriculture Greenhouse Environment Monitoring System Based on IOT Technology," International Conference on Intelligent Transportation, Big Data and Smart City, Halong Bay, 2015.

[5] "Zigbee," Digi, Available at: https:/www.digi.com/resources/standardsand-technologies/rfmodems/zigbee-wirelessstandard. [Accessed 2017 March 20].

[6] V. V. h. Ram, H. Vishal, S. Dhanalakshmi and P. M. Vidya, "Regulation of water in agriculture field using Internet Of Things," IEEE Technological Innovation in ICT for Agriculture and Rural Development (TIAR), Chennai, 2015.

[7] J. Shenoy and Y. Pingle, "IOT in agriculture," 3rd International Conference on Computing for Sustainable Global Development (INDIACom), New Delhi, 2016. 
[8] "Polyhouse farming advantages and benefits", Available at: http://www.agrifarming.in/polyhouse-farmingprofits/. [Accessed 3 March 2017].

[9] "Soil pH," Wikipedia, Available at: https://en.wikipedia.org/wiki/Soil_pH. [Accessed 4 March 2017].

[10] A. Abdullah, S. A. Enazi and I. Damaj, "AgriSys: A smart and ubiquitous controlledenvironment agriculture system," 3rd MEC International Conference on Big Data and Smart City (ICBDSC), Muscat, 2016.

[11] "Multiple Input Multiple Output (MIMO)," Radio Electronics.com, [Online]. Available: http://www.radio-

electronics.com/info/antennas/mimo/multipleinput-multiple-output-technology-tutorial.php. [Accessed 26 March 2017].

[12] N. Gondchawar and R. S. Kawitkar, "Smart Agriculture Using IoT and WSN based Modern technologies," International Journal of Innovative Research in Computer and Communication Engineering, vol:4, no:6, 2016.

[13] "Raspberry PI", Available at: https://www.raspberrypi.org/. [Accessed 22 March 2017].

[14] S. K. Nagothu, "Weather based smart watering system using soil sensor and GSM," 2016 World Conference on Futuristic Trends in Research and Innovation for Social Welfare (Startup Conclave), Coimbatore, 2016.

[15] N. Agrawal and S. Singhal, "Smart drip irrigation system using raspberry pi and arduino," International Conference on Computing, Communication \& Automation, Noida, 2015.

[16] "Arduino," Arduino, Available at: https://www.arduino.cc/. [Accessed 24 March 2017].

[17] N. Putjaika, S. Phusae, A. Chen-Im, P. Phunchongharn and K. Akkarajitsakul, "A control system in an intelligent farming by using arduino technology," Fifth ICT International Student Project Conference (ICTISPC), Nakhon Pathom, 2016.

[18] S. Khashirunnisa, B. K. Chand and B. L. Kumari, "Performance analysis of Kalman filter, fuzzy Kalman filter and wind driven optimized Kalman filter for tracking applications," 2nd International Conference on Communication Control and Intelligent Systems, Mathura India, 2016.

[19] A. Kapoor, S. I. Bhat, S. Shidnal and A. Mehra, "Implementation of IoT (Internet of Things) and Image processing in smart agriculture,"
International Conference on Computation System and Information Technology for Sustainable Solutions (CSITSS), Bangalore, 2016.

[20] "MATLAB," MathWorks, Available at: https://www.mathworks.com/products/matlab. html. [Accessed 26 March 2017].

[21] C. A. et. al, "Wireless sensing and control for precision Green house management," Sixth International Conference on Sensing Technology (ICST), Kolkata, 2012.

[22] P. M. Jacob, Muhammed Ilyas H, J. Jose and J. Jose, "An Analytical approach on DFD to UML model transformation techniques," 2016 International Conference on Information Science (ICIS), Kochi, 2016, pp. 12-17.

[23] Mary Shaw, David Garlan, 'Software Architecture: Perspectives on an Emerging Discipline', Prentice Hall, 1996.

[24] Y. Ducq and D. Chen, 'How to measure interoperability: Concept and approach,' 2008 IEEE International Technology Management Conference (ICE), Lisbon, 2008, pp. 1-8.

[25] P. M. Jacob and M. Prasanna, "A Comparative analysis on Black box testing strategies," 2016 International Conference on Information Science (ICIS), Kochi, 2016, pp. 1-6. 